\title{
Review on Internal Auditing Reports of Inventory Commodities and Whether Quality Internal Control Is Aid the External Auditor in Institution Industry in Sudan : Study on Manufactures Classes
}

\author{
DR: EZZAT KAMAL ABDALLA MOUSA \\ BISHA UNVERSITY -KSA \\ UNVERSITY OF GARDEN CITY -SUDAN \\ ALAHFAD UNVERCITY \\ EMAIL: EZZKAMAL@HOTMAIL.COM
}

\begin{abstract}
This study is represented the internal audit to whether coincidences employee behavior and objects institutions operation for achieved, in the large institution is necessary to explanation relation between authority and responsibilities and identified jurisdictions and assignment to any one employees that will be represented map organization so the regulation the Research aim to achieved the Applying study in revaluation and review inventory in system internal control and to what extend the correct data at inventory Presented report to reflect risk practical side on count inventory The shorts in explain internal control from procedures that may face risk audit so that create negative final audit report to firm assurance and Check the correct and judications and measures control that is following in firm with precisely control in inventory during and after process internal control The research problem to deal with the following case to whether The procedures applying in count inventory is represented sufficient procedures to help external audit and opinion auditor is neutral The following procedures is weak in check inventory is part on organization diagram for firm that reflect point weak in firm so that create environment chaos in firm, Research Important is represented clarified and will understanding the characteristic basically internal control The risk statement in revaluation inventory in system internal control, The effect interdisciplinary overlap in side firm and to whether effects annually audit report Research time limits. The research cover one firm working on business glass for the period 2013-2014, research Hypothesis is build the main research hypothesis is building to there is relation between revaluation internal audit on inventory and procedures following with external auditor report research methodology to achieve the purpose of research through two method deductive approach ,Analytical \& Description Research : that is dependent on specific and accurate description for applying effective review the inventory according the method applying in firm and acknowledge weak point in that way which is following to check inventory and the whether statement coming through study case to one firm company Sudanese glass manufactures through collect facts and data available in system internal control recommendation to applying more study relate CAATs that may more effective to review inventory, Uses or employment more professional training staff The firm must use program training for time to time Separate the employment job in diagram firm that may help role in firm Review to HR to employee to define is qualified or not ,Use software advances with internal control training staff in this soft ware
\end{abstract}

Keywords :CAATs, inventory count, warehouse manager, audit team ,procedure

DOI: $10.7176 / \mathrm{EJBM} / 12-14-07$

Publication date:May $31^{\text {st }} 2020$

\section{Introduction}

The main point of this study is represented the internal audit to whether coincidences employee behavior and objects institutions operation for achieved, in the large institution is necessary to explanation relation between authority and responsibilities and identified jurisdictions and assignment to any one employees that will be represented map organization so the regulation and procedures and implementation methods in that official organizations represented control accounting and protection assets and records assurances for collects of data accounting that can dependent on also should be attention to necessary separate among the jurisdiction and responsibilities between employees and Clearfield power that determined position responsibilities inside the organization the main point the research to achieved applying study in assessing the inventory and checkup that working internal control additional to what that data is correct and pratical designed inventory review and will understanding internal business environment the main important of this research to clarified the will understanding of basic characteristic the internal control and statement risk to whether the review inventory in internal control the effects the relations and jurisdiction inside the organization how this effect in annually audit report that report point out that short in system internal audit in relate that procedures to face risks audit that may create negative report audit report finally against institution and assurances the audit procedures and authorization and measures control that applying in this institution that may guarantee precisely control inventory during and 
after internal audit, the hypothesis of this research build that relation between valuation the internal audit in the inventory and procedures applied with the external audit report the research achievement the target through deductive approach that applying theoretical review for researches and books review in internal audit from fundamental applying internal descriptive analytical method that depended on exactly descriptions effective implementation in account review inventory according the measures applying in the organization and acknowledge the internal weak point in the steps in inventory count review

\section{Research aim:}

The reseach aimed to achieved the following:

- Applying study in revaluation and review inventory in system internal control and to what extend the correct data at inventory

- Presented report to reflect risk practical side on count inventory

- The shorts in explain internal control from procedures that may face risk audit so that create negative final audit report to firm

- $\quad$ assurance and Check the correct and judrictions and measures control that is fellowing in firm with precisely control in inventory durig and after process internal control

\section{Problems research:}

The research problem to deal with the following case :

- The procedures applying in count inventory is represented sufficient procedures to help external audit and opinion auditor is neutral

- The following procedures is weak in check inventory is part on organization diagram for firm that reflect point weak in firm so that create environment chaos in firm

\section{Research Important :}

- Clarified and will understanding the characteristic basically internal control

- The risk statement in revaluation inventory in system internal control

- The effect interdisciplinary overlap in side firm and to whether effects annually audit report

\section{Research limits:}

The research cover one firm working on business glass for the period 2013-2014

\section{Research Hypothesis :}

the main reseach hypothesis is building to:

there is relation between revaluation internal audit on inventory and procedures following with external auditor report

\section{Research methodology:}

to achieve the purpose of research through two method:

\section{Deductive approach :}

Analytical \& Description Research : that is dependent on specific and accurate description for applying effective review the inventory according the method applying in firm and acknowledge weak point in that way which is following to check inventory and the whether statement coming through study case to one firm company Sudanese glass manufactures through collect facts and data available in system internal control This reseach split tow section review the internal report audit applying case study

\section{Section One:}

Internal report how the procedures review inventory count according GM presented and external audit team report:

Lily window glass co.(lily) is a glass manufactures which operates from a large production facility where it undertakes continuous production 24 hours seven aday a week . also on this site are two warehouse ,where the company raw material and finished goods are stored lily year end 31 December, Lily is finalizing the arrangement for the year end in inventory count which is to be undertaken on 31 december 2015 The finished windows are stored within 20 aisles of the first ware house. the second warehouse is for large piles raw material such as sand, used in the manufactures of glass . the following arrangements have been made for the inventory count:The warehouse manager will supervise the account as he is most familiar with the inventory there will be ten team of counters and each team will contain two member of staff ,one from the finance and one the manufacturing 
department. None of the warehouse staff other than the manager will be involved in the count Each team will count an aisle of finished goods by counting up and then down each asile . as this process is systematic it is not felt that the will need to flag area once accounted. Once the team has finished counting an asile the will hand in their sheets and be given a set for another aisle of the warehouse . in addition to the above to assist with the inventory counting there will be two teams of counters from the internal audit department and they will perform inventory counts .

Section two: result on report

Remarkable Points On This Report:

1- The warehouse manager is planning to supervise the inventory count . whilst he is familiar with inventory he has overall responsibility for the inventory and so is not independent he may want to hide inefficiencies and any issues that arise so that his department is not critics .

Recommendations of this point:

alternative supervisor who is not normally involved with inventory such as internal audit manager should supervisor the inventory count the warehouse manager and his team should not be involved in count at all.

2- There are ten teams of counters each team having two members of staff .however, there is no clear division of responsibilities within the team therefore both members of staff could count together rather than checking each other count :and error in their count may not be identified

Recommendations of this point:

each team should be informed that both members are required to count their assigned inventory separately therefore one count and the second member checks that the inventory has been counted correctly

3- the internal audit team are undertaken inventory counts rather than reviewing the controls and performing sample test count .their role should be focused on firming the accuracy of the inventory counting procedures

Recommendations of this point:

the internal audit counters should sample check the counting undertaken by the ten teams to provide an extra control over the completeness and accuracy of the count

4- once area are counted the team are not flagging the aisles as completed .therefore there is the risk that some area of the warehouse could be double counted or missed .

Recommendations of this point:

all aisles should be flagged as complete once the inventory has been counted in addition, internal audit or the count supervisor should check at the end of the count that all 20 aisles have been flagged as completed

5 - inventory not listed on sheets to be entered onto separate sheets which are not sequentially numbered there for the supervisor will be unable to ensure the completeness of all inventory sheets

Recommendations of this point:

each team should be given blank sheet for entering any inventory count which is not on their sheets .this blank sheets should be sequentially numbered any unused sheets should be retuned at the of the count and the supervisor should be check the sequence of all sheets at the end of the count

-6 The sheets are completed in ink and are sequentially numbered ,however the is no indication that they are signed by the counting team .therefore if any issue arise with the counting in an aisle, it will be difficult to follow up as the identity of the counting team will not be known

Recommendations of this point:

all inventory sheets be signed by the relevant team upon completion of an aisle, when the sheets are retuned the supervisor should check that they have been signed

7- The damage goods are not being stored in central area and instead the counter is just noting on the inventory sheets the level of damage however it will be difficult for the finanace team to decide on an appropriate level of write down if they are not able to see the damage goods in addition ,if these goods are left in aisles .they could be inadvertently sold to customer or moved to another aisles

Recommendations of this point:

damage goods should be clearly flagged be the counting teams and at the end of the count appropriate machinery should be used to move all damage windows to centeral location this will avoid the risk of selling these goods .a senior member of the finance team should then inspect these goods to assess the level of any write down or allowance

8- The company is undertake continuous production and so there will be movement of goods during the count inventory records could be under/overstated if goods are missed or double counted due to movement in the warehouse .

recommendations of this point

it is not practical to stop all inventory movement as the production needs to continue however any raw material required for 31 December should be estimated and put to one side will be work -in -progress the goods which are manufactured on 31 December should be stored on one side and at the end of the count should be counted 
once and included within finished goods any goods received from supplier should be stored in one location and counted once at the end and included as part of raw material, goods to be dispatched to customer should be kept to minimum for the day of the count

9- the warehouse manager is to assess the level of work -in -progress and raw material in the past specialist has undertaken this role it. Is unlikely that the warehouse manager has the experiences to assess the level of of work -in -progress as this is something's that the factory manager would be more familiar

Recommendations of this point:

as specialist should be utilized to assess both of work - in - progress and quantities of raw material in addition whilst the warehouse manager is familiar with the raw material if he makes as mistake in assessing the quantities then inventory could be materially misstated .with regard to the warehouse manager he could estimate the raw material and the specialist could be check this would give an indication as to whether he is able to accurately assess the quantities for subsequent inventory during the procedure the inventory count it is observe the counting teams of lily to confirm wehether the inventory count instructions are being followed correctly as well as select a sample and performs test counts from inventory sheets to warehouse aisle and from warehouse aisle to inventory sheets to will confirm the procedures for individual and segregating damaged goods are operating correctly with select a sample of damaged items as noted on the inventory sheets and inspect these windows to confirm whether the level of damage is correctly additional. the observe the procedure for movement of the inventory during the count to confirm that no raw material or finished goods have been omitted or count twice .obtain a photocopy of the completed sequentially numbered inventory sheets for follow up testing on the final audit identify and make a note of the last goods received notes(GRNs) and goods dispatch notes(GDNs) for 31december in order to perform cut-off procedures .that mean observe the procedures carried out by the warehouse manager in assessing the level of work -in - progress and consider the reasonable of any assumptions used . with discuss the warehouse manger how he has estimated raw material quantities to the extent that it is possible . re-performed the procedures adopted by the warehouse manager .identify and record any inventory held for third parties (if any) and confirm that it is excluded from the count

the audit team can used soft ware to calculated inventory days for the year -to- date to compare against the prior year to identified whether inventory is turning over slower .as this may be an indication that it is overvalued as well as the audit software can be utilized to produce an aged inventory analysis to identified any slow moving goods which may require write down or allowance .cast the inventory listing to confirm the completeness and accuracy of inventory also can be use audit software to select representative sample of items for testing to confirm net realizable value and /or cost .

audit software can be utilized to recalculate cost and net realizable valued for sample of inventory the CAATs can be used to verify cut -off by testing whether the dates of last GRNs and GDNs recorded relate to pre year end and that any with date of 1 January 2013 onword have been excluded from the inventory record CAATs can be used to confirm whether any inventory adjustment noted during the count have been correctly update into final inventory records. the advantage of using the audit team to test large volume of inventory data accurately and quickly so if CAATs are utilized on the audit of lily .then as long as they do not change their inventory system they can be cost effective after setup the CAATs can test program control within the inventory system as well as general IT control such as password additional allows the team to test the actual inventory system and record rather than print outs from the system which could be in correctly also reduce the level of the human error in testing and hence provide better quality audit evidence also result can be compared with traditional audit test ing if :these two sources agree then overall audit confidence will increase the use of CAATs free ups audit team members to focus on judgment and high risk area rather than number of crunching .

Recommendation on study case :

1- Applying more study relate CAATs that may more effective to review inventory

2- Uses or employment more professional training staff

3- The firm must use program training for time to time

4- Separate the employment job in digram firm that may help role in firm

5- Review to HR to employee to define is qualified or not

6- Use software advances with internal control training staff in this soft ware

\section{Reference}

- $\quad$ A.Rnold, Performance Appraisal for upper Management, M city Government Public Administration Review, Riyadh, 1986

- Adolph Matz, Cost Accounting Planning and Control, Oklahoma, South Western Publication ,1980,

- $\quad$ Anthory A. Atkinson, Management Accounting, 4 ${ }^{\text {th }}$ edit,New York, Mc Grow Hill Publisher P.127, 2004.

- $\quad$ Brimson, j Technology Accounting Management 1989

- $\quad$ Charles .T. Horngern, Introduction Management Accounting, 11 ${ }^{\text {th }}$ edit., New York, Upper Saddle 
Review Publisher, 1999,

- $\quad$ Charles, T. Horgren, Cost Accounting Managerial Emphasis, 13 ${ }^{\text {th }}$, ed. New York, 1992

- David Russell, Ashok Patel,Cost Accounting An Essential Guide, London, Publisher Library of Congress Cataloging -in-Publication Data .2002

- $\quad$ Don. R. Nansen, Cost Management Accounting and Control, New York, Mc Hill Publish,1997

- Dr. Ray H. Garrison, Managerial Accounting Concept for Planning Control and Decision Making,5th edit, Publish in Canada ,2001

- Dr.Salemonson,Survey of Basic Accounting,3th.ed,Washintgon Library Congress, 1981

- $\quad$ Gauther Norman, Production and Operation Management $6^{\text {th }}$ ed, Washington, Dryden Press .1998, 